\title{
Strong postmidnight equatorial ionospheric anomaly observations during magnetically quiet periods
}

\author{
Endawoke Yizengaw, ${ }^{1,2}$ Mark B. Moldwin, ${ }^{1,3}$ Yogeshwar Sahai, ${ }^{4}$ and Rodolfo de Jesus ${ }^{4}$
}

Received 24 June 2009; revised 9 September 2009; accepted 16 September 2009; published 8 December 2009.

[1] We have examined the quiet time equatorial electrodynamics of the ionosphere in the postmidnight sector using satellite, GPS total electron content (TEC) and ionosonde data. ROCSAT-1 vertical drift data are used to estimate the equatorial ionosphere electrodynamics, TOPEX altimeter and GPS TEC are used to obtain the density structure of the ionosphere. Ionosonde data measure the postmidnight $F$ layer height as function of local time. We analyzed 4 years $(2001-2004)$ of quiet time $(K p \leq 3)$ observations in the postmidnight sector. We found that very strong equatorial ionospheric anomalies (EIAs) in the postmidnight (0100-0500 LT) sector during magnetically quiet periods are common and are capable of disrupting satellite communication and navigation systems. The coordinated multi-instrument observations clearly demonstrate that these strong EIAs are not simply the EIAs observed in earlier local time sectors that have corotated into the postmidnight sector as has been suggested by previous studies. We demonstrate that they are triggered by a reversed vertically upward drift, which is suggested to be generated by thermospheric neutral wind through $F$ region dynamo. This clearly demonstrates that the Earth's postmidnight ionosphere is dynamic even in magnetically quiet periods contrary to simple theoretical model predictions.

Citation: Yizengaw, E., M. B. Moldwin, Y. Sahai, and R. de Jesus (2009), Strong postmidnight equatorial ionospheric anomaly observations during magnetically quiet periods, J. Geophys. Res., 114, A12308, doi:10.1029/2009JA014603.

\section{Introduction}

[2] Vertical plasma drift, which is one of the most important processes that control the large-scale distribution of plasma in the ionosphere and plasmasphere, at the geomagnetic equator is generally downward at night and upward during daytime [e.g., Woodman, 1970; Wang et al., 2008]. During nighttime the $F$ region dynamo becomes the dominant source of upward vertical plasma drift, especially during magnetically disturbed time [Hari and Murthy, 1995]. Because of the conductivity gradient enhancement across the terminator, the $F$ region dynamo becomes the dominant source of postsunset (prereversal) enhancement of strong vertical plasma drift. The impact of the prereversal enhancement can exist until midnight local time, especially during severe magnetic storm periods [e.g., Lyon and Thomas, 1963; Rao and Malthotra, 1964]. Recently, McDonald et al. [2008] observed postmidnight equatorial ionospheric anomaly (EIA) signatures during quiet periods and attributed it to the prereversal enhance-

\footnotetext{
${ }^{1}$ Institute of Geophysics and Planetary Physics, University of California, Los Angeles, California, USA.

${ }^{2}$ Now at Institute for Scientific Research, Boston College, Chestnut Hill, Massachusetts, USA.

${ }^{3}$ Now at Department of Atmospheric, Oceanic and Space Sciences, University of Michigan, Ann Arbor, Michigan, USA.

${ }^{4}$ Instituto de Pesquisa e Desenvolvimento, Universidade do Vale do Paraíba, São José dos Campos, Brazil.
}

Copyright 2009 by the American Geophysical Union. 0148-0227/09/2009JA014603 ment, suggesting that the EIA persisted into the postmidnight hours. The other possible cause for the postmidnight EIA is the nightside reversed vertically upward drift as has been observed with radar observations during disturbed time [e.g., Woodman, 1970; Wang et al., 2008]. These studies concluded that the nightside reversed upward drift was caused by the $F$ region dynamo. The same studies suggested that substorm activity could be the possible triggering mechanism for the nightside reversal of vertical drift. However, the triggering mechanism for quiet time strong $F$ region dynamo; thus, EIA signatures in the postmidnight sector is still an open question.

[3] In the present study, we use plasma drift observations from the ROCSAT-1 satellite to investigate the primary source of quiet time strong EIA and $F$ region uplift observed by TOPEX altimeter total electron content (TEC) and ionosonde, respectively, in the postmidnight sector.

\section{Data and Methods of Analysis}

[4] The TOPEX/POSEIDON satellite, which was operational from August 1992 until January 2006, carried a dual frequency radar altimeter, from which the vertical TEC below the orbiting altitude of the satellite (only over the ocean) can be obtained [Scherliess et al., 2008, and the reference therein]. TOPEX was orbiting at an altitude of $1336 \mathrm{~km}$ with a $66^{\circ}$ inclination. We used the altimeter TEC data between January 2001 and December 2004. During these periods only quiet time $(K p \leq 3)$ strong TEC's EIA signatures with TOPEX equatorial crossings local time 


\section{(a)}

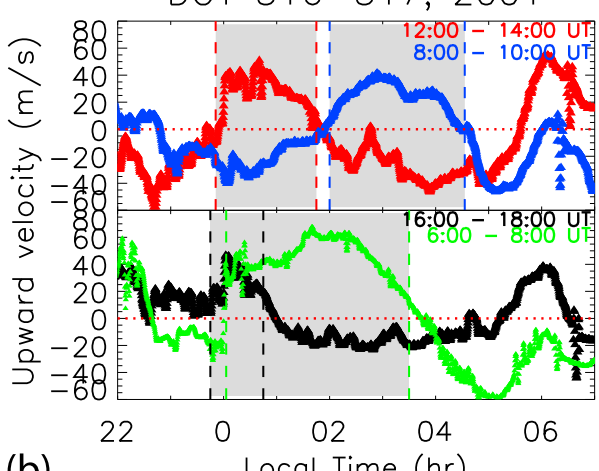

(b)

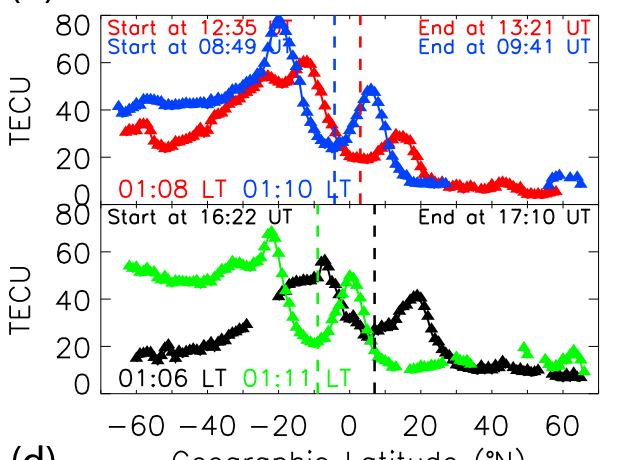

(d) (c)

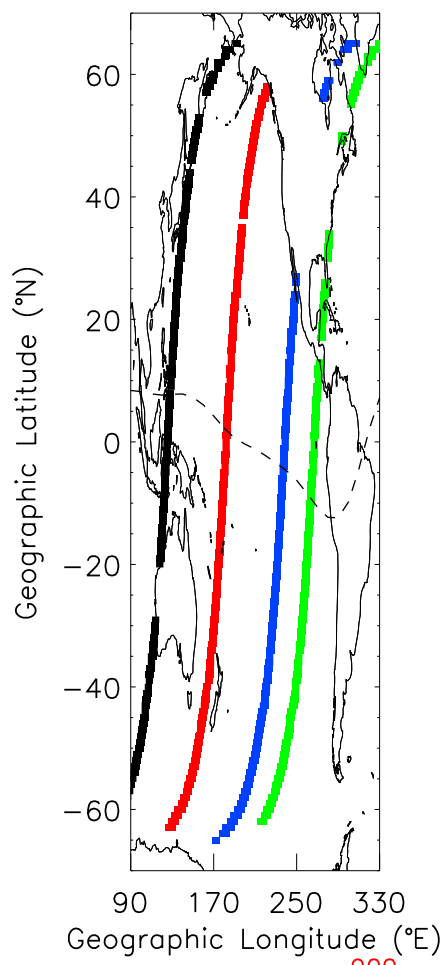

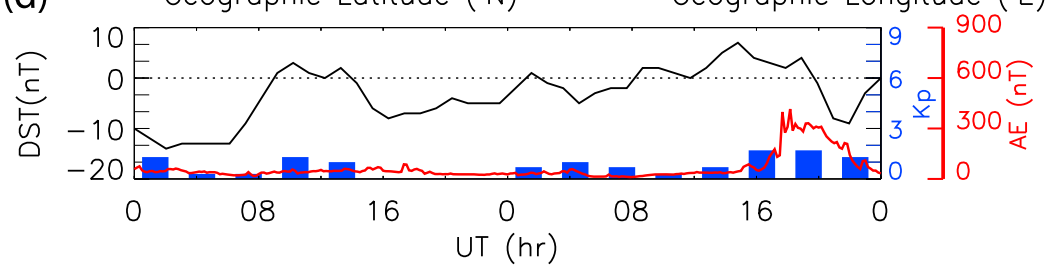

Figure 1. (a) The local time variations of the vertically upward drifts observed by ROCSAT-1 on 13 November 2001. The universal time interval for each segment is shown at top right corner of each plot. The shaded regions that are inscribed by the correspondingly colored vertical dashed lines depict the reversed upward drifts in the postmidnight sectors. (b) The TOPEX altimeter TEC in which the start and end time of TOPEX pass is given at the top of each plot, and the colored vertical dashed lines indicate the location of geomagnetic equator for the corresponding colored curves. The local time crossing of each pass is also identified at the bottom of each plot. (c) The geographic locations of each TOPEX pass. The horizontal dashed curve depicts the location of the geomagnetic equator. (d) The geomagnetic indexes, Dst (black curve), $K p$ (blue bars), and $A E$ (red curve), of the day.

between 0000 and 0500 LT were identified. The strength of EIA is defined as the TEC difference between the peak and trough of EIA ( $\triangle$ TEC). For this study only EIA signatures with $\triangle$ TEC greater than 15 total electron content unit (TECU) $\left(1 \mathrm{TECU}=10^{16} \mathrm{el} \mathrm{m}^{-2}\right)$ are considered as significant. In the case of landmass coverage on one side of the hemispheres, the same criterion is applied for those passes that have clear anomaly peak only at one hemisphere, either on the Southern Hemisphere or Northern Hemisphere.

[5] The ROCSAT-1 satellite provided plasma drift observations from March 1999 to June 2004 at an altitude of $600 \mathrm{~km}$ in a circular orbit with an inclination of $35^{\circ}$ [e.g., Yeh et al., 1999]. We segmented drift data from ROCSAT-1 by the universal time intervals with in the margin of the corresponding TOPEX passes so that the local time of each segment ( $2 \mathrm{~h}$ UT period) varies from $0000 \mathrm{LT}$ to $2400 \mathrm{LT}$. The ROCSAT-1 vertical drift velocities are then averaged over $20 \mathrm{~s}$ in local time. We used Fejer et al. [2008a] technique to extract the vertical drift velocity from ROCSAT-1 drift observations.

\section{Observation}

[6] Figure 1 show examples of quiet time ROCSAT-1 vertical drift velocities (positive upward) and TOPEX altimeter TEC data observed on 13 November 2001 (day 317 ) in the postmidnight sector. The ROCSAT-1 vertical velocity data were divided into two groups: (1) data observed when EIA signatures were detected and (2) data observed with no EIA signatures. We take the average of the second group for at least the 3 quietest days available in each month (from now on referred to as "monthly average"). Finally, in order to magnify the reversed postmidnight vertical drift the monthly average value was subtracted from each day of the first group for the given universal time interval and plotted as a function of local time as shown in 

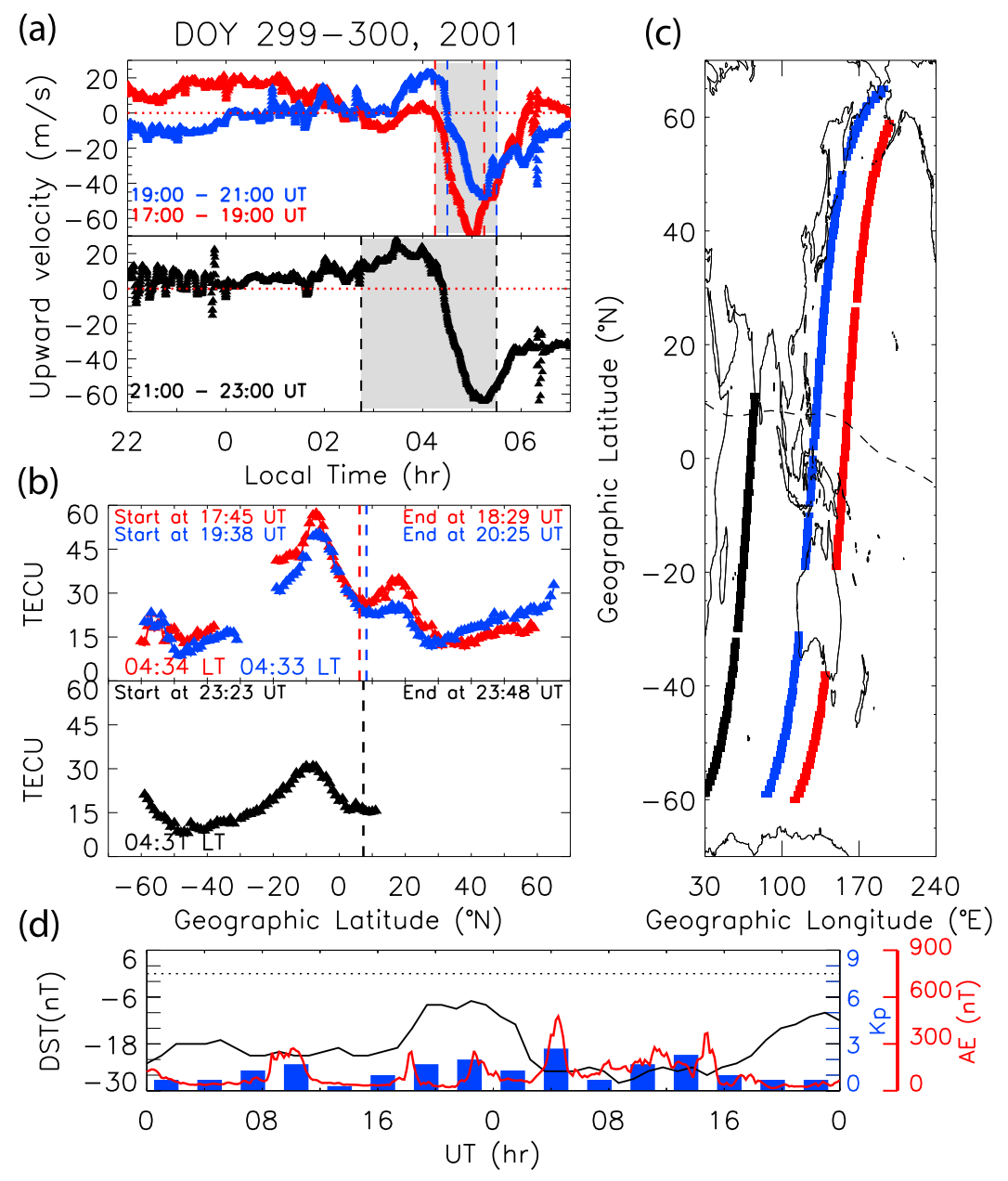

Figure 2. As for Figure 1 but showing data observed on 27 October 2001.

Figure 1a. Different colored curves represent different $2 \mathrm{~h}$ segments in the margin of the corresponding TOPEX passes shown in Figure 1c. All four curves show significant upward drift in the postmidnight sector as shown inside the shaded regions. The correspondingly colored TOPEX altimeter TEC data are shown in Figure 1b. The altimeter TEC, which is averaged over $1^{\circ}$ in latitude, reveals a very strong EIA signature with $\triangle \mathrm{TEC}$ up to about $60 \mathrm{TECU}$ (blue curve). The weakest EIA signature, with $\triangle \mathrm{TEC}<$ 35 TECU, of the four TOPEX passes is shown by the black curve.

[7] Figure 2 is in the identical format as Figure 1, but it presents a pronounced EIA signature at a later local time ( $\sim 0430$ LT) observed on 27 October 2001 (day 300). Similarly, in Figure 2 the TOPEX altimeter TEC clearly reveals a significant EIA as shown in Figure $2 b$. Their corresponding ROCSAT-1 postmidnight vertical drift values are also shown in Figure 2a.

[8] The digital ionosonde at S. J. Campos $\left(23.2^{\circ} \mathrm{S}, 45.9^{\circ} \mathrm{W}\right)$, Brazil, also shows nighttime $F$ layer $\left(h^{\prime} F\right)$ height rise on 26-27 October 2001 as shown in Figure 3. The $h^{\prime} F$ starts increasing at about 1700 LT and then eventually reduces back to its level before 1700 LT and maintains the same altitude level until it surges upward again at 0315 LT. However, when the $h^{\prime} F$ shows unusual enhancement in the postmidnight sector, $f_{\mathrm{o}} F_{2}$ could not be estimated due to the presence of strong spread $F$.

[9] Figure 4 shows the GPS TEC extracted, using the technique described by, e.g., Yizengaw et al. [2005], from GPS receivers stationed at about $80^{\circ} \mathrm{W}$ meridian on 27 April 2003. Figure 4 presents vertical TEC as a function of geomagnetic latitudes, showing the EIA evolution throughout the night. It enhanced during the evening local time (see Figure $4 \mathrm{~b}$ ) and is eventually reduced through time and almost disappears by 2330 LT (red curve in Figure 4c). Surprisingly, the disappeared EIA is revived at a later local time and significantly reappears in the postmidnight sector as shown in Figure 4d.

[10] Figure 5 shows statistical histogram plots, using 4 years of ROCSAT-1 drift (red bars) and TOPEX altimeter TEC (black bars) data. Out of the 4 years of data, we found 132 quiet days $(K p \leq 3)$ with TOPEX equatorial crossings between 0000 and 0500 LT. During this time there were about 730 equator crossing TOPEX passes. As can be seen in Figure 5d, the equatorial crossings of those TOPEX passes have a reasonable even monthly distribution during the local time interval mentioned above. The selection of TOPEX passes was based on their clear geomagnetic equator crossing, i.e., passes that do not have clear equatorial crossing were not suitable passes to detect EIA signa- 
26 - 27 OCTOBER 2001

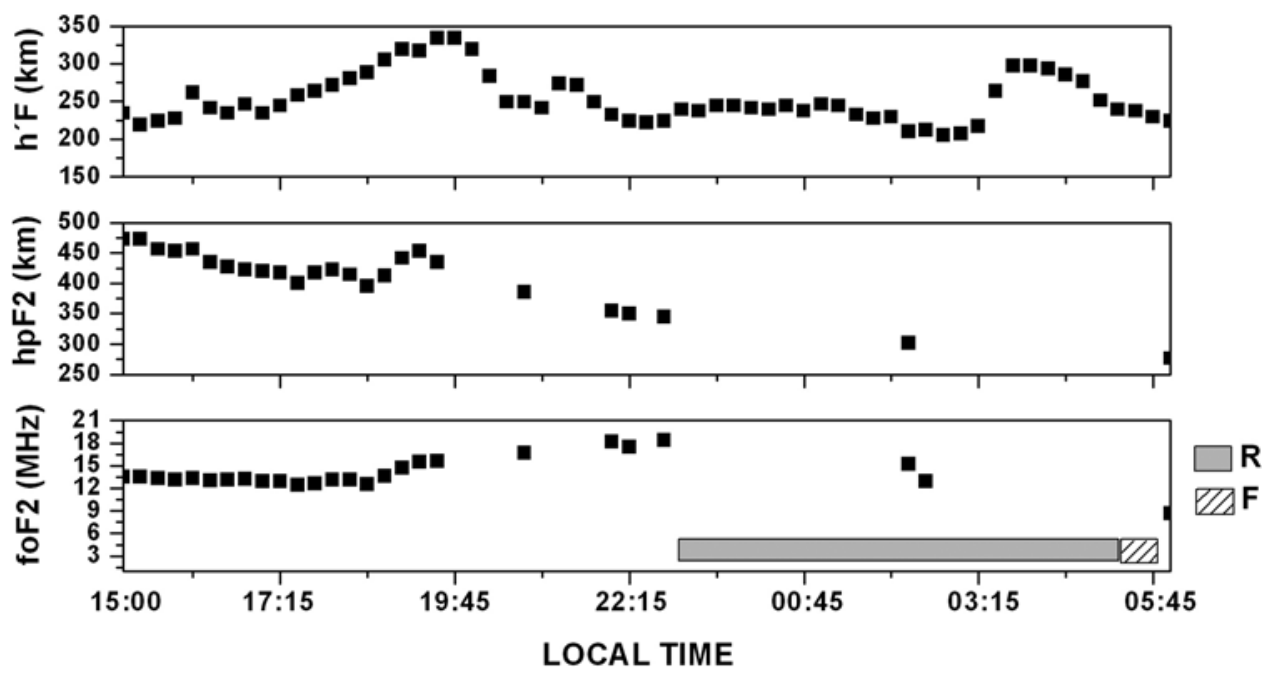

Figure 3. The local time variation of (top) $h^{\prime} F$, (middle) $h_{p} F_{2}$, and (bottom) $f_{o} F_{2}$ observed at S. J. Campos, Brazil.

tures and have been discarded. However, out of 132 total quiet days only 35\% (46 days) experienced strong EIA signature with $\triangle \mathrm{TEC}>15 \mathrm{TECU}$. In terms of the TOPEX passes, about $17 \%(\sim 120$ passes $)$ of the total 730 passes observed strong EIA signature. Similarly, we processed the corresponding ROCSAT-1 drift measurement data for those TOPEX passes (120 passes) that experienced EIA signatures and found significant reversed drift during the majority of corresponding TOPEX passes ( $\sim 72 \%$ of those 120 passes). There was a significant number of passes (about $28 \%$ of total passes) that detected strong EIA signatures without significant ROCSAT-1 reversed vertical drift observed in the postmidnight sector (see Figure 5). The geomagnetic conditions of the 46 days of strong EIA were as follow: about 37\% (17 days) with $K p \leq 3$, about 52\% (24 days) with $K p \leq 2$, and about $11 \%$ (5 days) with $K p \leq 1$.

\section{Discussion}

[11] The simultaneous ROCSAT-1 vertical drift and the TOPEX altimeter observations of EIAs provide the opportunity to examine the electrodynamics that governs the quiet time equatorial anomaly in the postmidnight sector. As shown in the selected example, Figures 1 and 2, the EIAs observed by TOPEX are clearly contemporary with the postmidnight upward vertical drift velocities. Because of TOPEX's limited local time coverage per day, we are unable to observe the evening EIA signature throughout the night and into the postmidnight local time sector to directly test the hypothesis that the postmidnight EIA is due to the corotation of the dusk EIA past midnight as has been attributed by previous studies [e.g., McDonald et al., 2008]. However, as shown in Figure 4 the evolution of EIA reveals its development in the evening sector and disappearance around the premidnight sector. The reappearance of the disappeared EIA at a later postmidnight local time sector is evident as shown in Figure 4d. At the same local time sector, ROCSAT-1 detected (not shown) upward vertical velocity, indicating the revived EIA signature in the postmidnight sector is correlated to this reversed vertical drift. The expansion of the anomaly peaks from $\sim 18^{\circ}$ geomagnetic in the premidnight sector (Figures $4 \mathrm{~b}$ and $4 \mathrm{c}$ ) to $\sim 25^{\circ}$ geomagnetic in the postmidnight sector (blue dashed lines at $\sim \pm 25^{\circ}$ latitude in Figures $4 \mathrm{~d}$ and $4 \mathrm{e}$ ) indicates

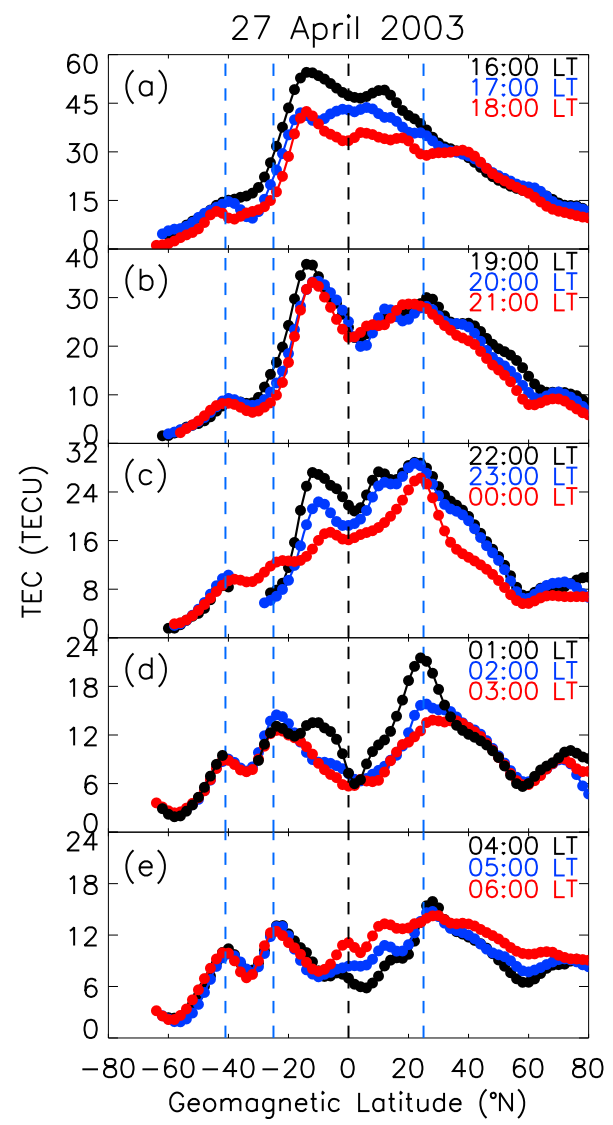

Figure 4. GPS TECs, which are averaged into an hour local time bin, is plotted as a function of geomagnetic latitude. Different colors in each panel represent different local time averages. The corresponding local time is given at the top of each panel. 
(a)
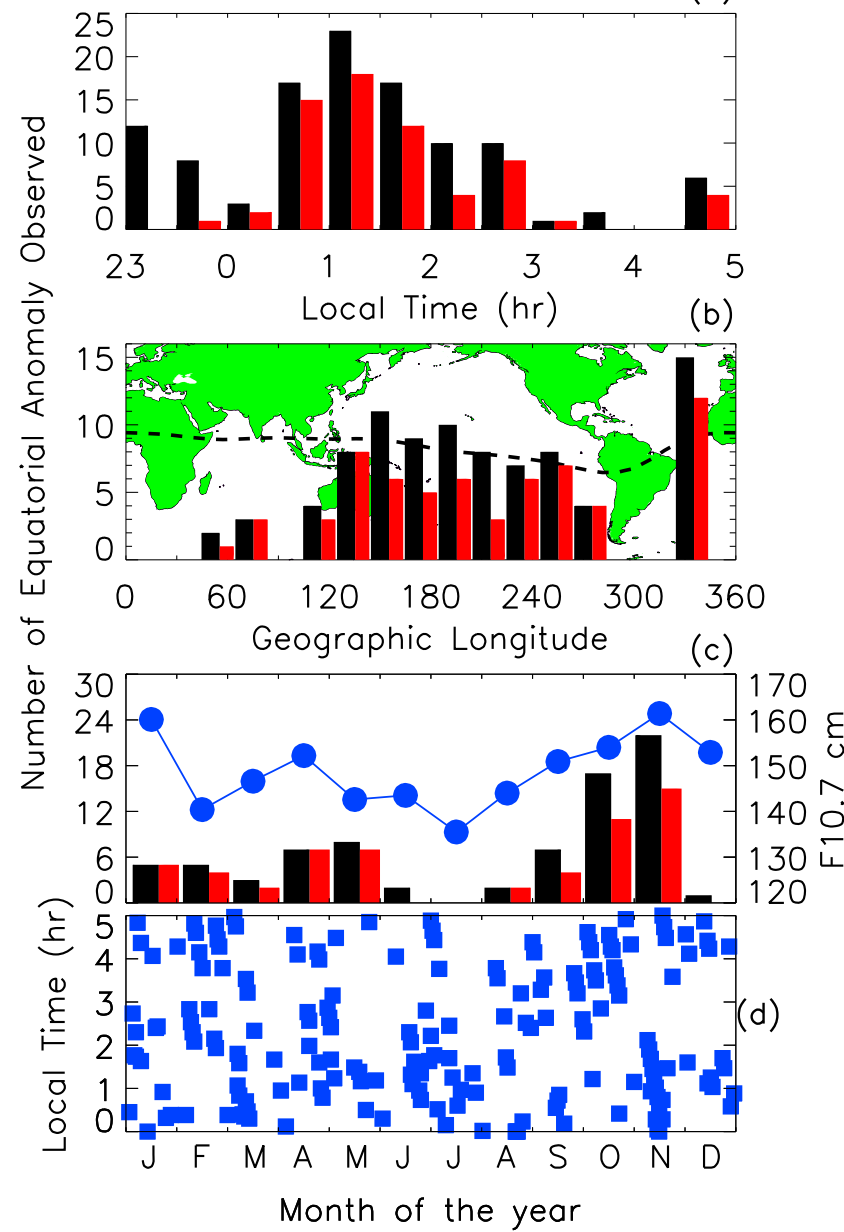

Figure 5. The histogram showing the number of quiet time EIA (black bars) and reversed vertical drift (red bars) observations as a function of (a) local time, (b) longitude, and (c) season. The horizontal dashed line in Figure $5 \mathrm{~b}$ depicts the geomagnetic equator. The seasonal (quiet days average) variation of $F_{10.7}$ index (blue curve) is also shown in Figure 5c, and Figure 5d shows the monthly distribution of the equatorial crossings local time of TOPEX passes.

the existence of a new electrodynamic force that transport the plasma to higher altitudes, causing it to slip along geomagnetic field lines to higher latitudes [Mannucci et al., 2005]. However, the ground-based GPS TEC's EIA signature was not as strong as the EIA signature detected by TOPEX altimeter TEC, which estimates the integrated electron density over the ocean. Although it requires further investigation, from this single observation we can speculate that the difference may be due to the electrodynamic differences between the ocean and landmass, specifically the difference in gravity wave occurrence over the ocean than over the land [Barthelmie et al., 1996]. Gravity waves propagate upward and enhance the neutral wind at ionospheric altitudes [e.g., Singer et al., 1994]. The TEC enhancement shown in the Southern Hemisphere (blue dashed lines in Figure 4) in the latitude range around $40^{\circ}-45^{\circ} \mathrm{S}$ could be due to the meridional thermospheric wind that drives the $F$ layer plasma upward. This is the region where the wind-induced uplifting is most efficient [Jakowski et al., 1999].

[12] During magnetically quiet periods, the principal source of nighttime electric fields is the $F$ region dynamo triggered by thermospheric neutral winds [e.g., Fejer et al., 2008a]. The positive gradient of the $F$ region zonal neutral wind (increasing eastward with time) would result in an eastward electric field [Hari and Murthy, 1995], which then produces vertically upward drift velocity [Wang et al., 2008] and causes the formation of EIA signatures in the postmidnight sector. The observation and model simulation studies [Wang et al., 2008] show that the meridional electric fields resulting from the disturbance dynamo are only important in the nighttime, producing upward plasma drift. Figures 1 and 2 show exactly the same feature, which is upward vertical drifts and EIA signatures in the postmidnight sector. Singer et al. [1994] found that such enhancement of zonal neutral wind in the $F$ region could be due to internal atmospheric disturbances such as stratospheric warming. Recently, Goncharenko and Zhang [2008] observed a strong stratospheric warming during quiet time $(K p<3)$ on $23-26$ January 2008.

[13] The statistical data shown in Figure 5, which were averaged into $30 \mathrm{~min}$ local time bins (Figure 5a), show most of the EIA signatures occur between 0100 and 0300 LT. The very few EIA signatures observation between 0000 and 0030 LT is consistent with the argument that the postmidnight EIA signatures are not the remnants of the dusk EIA. If it is the remnant, we would have seen more EIA observations at earlier local times than later. In fact, during the premidnight sector (2300-0000 LT) the number of EIA observations decreases and reached to a minimum around midnight (Figure 5a). Additional TOPEX passes with equatorial crossing local time between 2300 and 0000 LT, based on the same selection criterion, have been processed and included only in Figure 5a in order to see the difference between premidnight and postmidnight EIA occurrence. Since the objective of this paper is the postmidnight EIA occurrence, the premidnight additional data have not been included in the remaining part of the statistical plots (Figures 5a-5d). The corresponding ROCSAT's reversed vertical drift shows similar trend, i.e., more reversed vertical drifts occurred between 0100 and 0300 LT and almost none during premidnight sector. Significant number of EIA as well as reversed vertical drifts are observed during early dawn (0400-0500 LT) sector. The in situ density data from the recently launched C/NOFS mission also repeatedly reveal clear EIA signatures in the early dawn sector [de La Beaujardière et al., 2009]. Ionosonde observations (Figure 3) also clearly shows the evening prereversal did not persist until the postmidnight sector, instead the second $h^{\prime} F$ surge and onset of spread $F$ at 0315 LT indicates the existence of new electrodynamic force that drives the $F$ layer upward. At the same local time (see Figure 2) both ROCSAT- 1 and TOPEX altimeter-observed reversed upward vertical velocity and EIA signatures, indicating the upward drift observed in the postmidnight sector is a global event.

[14] On the basis of TOPEX pass selection criteria mentioned in section 2, the longitudinal distribution of EIA and reversed drift observations (Figure $5 b$ ) shows more EIA and reversed drift occurred over the Pacific and 
Atlantic oceans than the Indian Ocean. This could be due to the location of geomagnetic equator relative to the continents in the Indian sector. A number of postmidnight EIA and reversed drift is also observed in the Atlantic Ocean longitudinal sector. The Pacific and Atlantic (in the vicinity of the African shore) are the regions where strong equatorial ionospheric irregularities and scintillation activities are often observed throughout the year [Hei et al., 2005].

[15] The seasonal distribution of EIA and reversed upward drift in the postmidnight sector (Figure 5c) shows a maximum number of postmidnight EIA and reversed drift observed during October and November. The second statistically significant number occurs in April and May. Hari and Murthy [1995], using 2 year (1989 and 1990) average ionosonde data obtained from Trivandrum station in India, also found the maximum vertical upward drift velocity in October and November in the postmidnight sector which is consistent with our observations. They attributed this to thermospheric neutral wind, because, using the HWM-90 thermospheric wind model, they also found similar seasonal trend for the neutral wind velocity (maximum wind speed in October and November). This could be due to temporal variations of the solar radio flux $\left(F_{10.7} \mathrm{~cm}\right)$, which can contribute to the heating of the atmosphere and thus enhancement of neutral wind. Interestingly, the 4 year (2001-2004) quiet days monthly average $F_{10.7}$ index exhibited similar seasonal variation with the first maximum in October-November (blue curve in Figure 5c). Previous studies show that as the $F_{10.7}$ index increases so does the nightside equatorial electrodynamic activity [e.g., Fejer et al., 2008b], which is consistent with our observations. In order to make sure if the seasonal difference may be due to the monthly distribution of TOPEX passes, we plotted the local time equatorial crossings of the passes as a function of days (Figure 5d). It shows even monthly distributions, indicating that the monthly distribution of TOPEX passes may not be the reason for seasonal difference that we observed. We also investigated the substorm onset timing using $\mathrm{Pi} 2$ pulsation during those quiet days when postmidnight EIA signatures were observed and found that only $22 \%$ of the EIA are correlated with substorm activity.

\section{Conclusions}

[16] The Earth's ionosphere is not always calm in the postmidnight sector during quiet periods as predicted by simple theoretical models. It commonly has significant EIA structures, which are not the remnants of EIA formed in the evening sector as has been claimed by previous studies. These anomalies are capable of distorting satellite communication and navigation systems [e.g., Doherty et al., 2004; de La Beaujardière et al., 2009]. Using independent observations, we demonstrated that the postmidnight anomalies are triggered by the reversed upward drifts that are suggested to be generated by thermospheric neutral wind through $F$ region dynamo. The triggering mechanism of the strong thermospheric neutral winds leading to enhanced $F$ region dynamo process is still not understood. This study found only about $22 \%$ of EIAs have a correlation with substorm activity, which is inconsistent with earlier observations mentioned in section 1 . Therefore, what generates stronger thermospheric neutral winds during quiet times in the postmidnight sector is still an open question for a significant number of events. Future coordinated multiinstrument observations, as well as modeling studies, are essential to have a clear global understanding of such strong anomaly formation in the postmidnight sector during magnetically quiet times.

[17] Acknowledgments. This work was supported by NASA IHY and Guest Investigator programs (NNX07AM22G and NNX08AF33G) and NSF grant ATM-0348398. The authors are indebted to the IGS for the GPS data. TOPEX altimeter TEC were processed and archived by Physical Oceanography DAAC at Jet Propulsion Laboratory, ROCSAT-1 data were processed and archived by National Central University, Chung-Li of Taiwan. The geomagnetic indexes $(D s t, K p$, and $A E)$ are obtained from World Data Center archived by Kyoto University.

[18] Amitava Bhattacharjee thanks the reviewers for their assistance in evaluating this paper.

\section{References}

Barthelmie, R. J., B. Grisogono, and S. C. Pryor (1996), Observations and simulations of diurnal cycles of near-surface wind speeds over land and sea, J. Geophys. Res., 101, 21,327-21,337, doi:10.1029/96JD01520.

de La Beaujardière, O., et al. (2009), C/NOFS observations of deep plasma depletions at dawn, Geophys. Res. Lett., 36, L00C06, doi:10.1029/ 2009GL038884.

Doherty, P., A. J. Coster, and W. Murtagh (2004), Space weather effects of October-November 2003, GPS Solut., 8(3), doi:10.1007/s10291-0040109-3.

Fejer, B. G., J. W. Jensen, and S.-Y. Su (2008a), Quiet time equatorial $F$ region vertical plasma drift model derived from ROCSAT-1 observations, J. Geophys. Res., 113, A05304, doi:10.1029/2007JA012801.

Fejer, B. G., J. W. Jensen, and S.-Y. Su (2008b), Seasonal and longitudinal dependence of equatorial disturbance vertical plasma drifts, Geophys. Res. Lett., 35, L20106, doi:10.1029/2008GL035584.

Goncharenko, L., and S.-R. Zhang (2008), Ionospheric signatures of sudden stratospheric warming: Ion temperature at middle latitude, Geophys. Res. Lett., 35, L21103, doi:10.1029/2008GL035684.

Hari, S. S., and B. V. K. Murthy (1995), Seasonal variations of equatorial night-time thermospheric meridional winds, J. Atmos. Sol. Terr. Phys., 57, 1241-1246, doi:10.1016/0021-9169(95)00007-O.

Hei, M. A., R. A. Heelis, and J. P. McClure (2005), Seasonal and longitudinal variation of large-scale topside equatorial plasma depletions, J. Geophys. Res., 110, A12315, doi:10.1029/2005JA011153.

Jakowski, N., S. Schlüter, and E. Sardon (1999), Total electron content of the ionosphere during the geomagnetic storm on 10 January 1997 J. Atmos. Sol. Terr. Phys., 61, 299-307, doi:10.1016/S13646826(98)00130-8

Lyon, A. J., and L. Thomas (1963), The F2-region equatorial anomaly in the African, American and East Asian sectors during sunspot maximum, J. Atmos. Terr. Phys., 25, 373-386, doi:10.1016/0021-9169(63)90170-3. Mannucci, A. J., B. T. Tsurutani, B. A. Iijima, A. Komjathy, A. Saito, W. D. Gonzalez, F. L. Guarnieri, J. U. Kozyra, and R. Skoug (2005), Dayside global ionospheric response to the major interplanetary events of October 29-30, 2003 "Halloween Storms", Geophys. Res. Lett., 32, L12S02, doi:10.1029/2004GL021467.

McDonald, S. E., K. F. Dymond, and M. E. Summers (2008), Hemispheric asymmetries in the longitudinal structure of the low-latitude night time ionosphere, J. Geophys. Res., 113, A08308, doi:10.1029/2007JA012876.

Rao, C. S. R., and P. L. Malthotra (1964), A study of geomagnetic anomaly during I.G.Y., J. Atmos. Terr. Phys., 26, 1075-1085, doi:10.1016/00219169(64)90093-5

Scherliess, L., D. C. Thompson, and R. W. Schunk (2008), Longitudinal variability of low-latitude total electron content: Tidal influences, J. Geophys. Res., 113, A01311, doi:10.1029/2007JA012480.

Singer, W., et al. (1994), Geomagnetic influences upon tides winds from MLT radars, J. Atmos. Sol. Terr. Phys., 56, 1301-1311, doi:10.1016 0021-9169(94)90068-X.

Wang, W., J. Lei, A. G. Burns, M. Wiltberger, A. D. Richmond, S. C. Solomon, T. L. Killeen, E. R. Talaat, and D. N. Anderson (2008), Ionospheric electric field variations during a geomagnetic storm simulated by a coupled magnetosphere ionosphere thermosphere (CMIT) model, Geophys. Res. Lett., 35, L18105, doi:10.1029/2008GL035155.

Woodman, R. F. (1970), Vertical drift velocities and East-West electric fields at the magnetic equator, J. Geophys. Res., 75, 6249-6259, doi:10.1029/JA075i031p06249.

Yeh, H.-C., et al. (1999), Scientific mission of the IPEI payload onboard ROCSAT-1, Terr. Atmos. Ocean, supplement, 19-42. 
Yizengaw, E., M. B. Moldwin, P. L. Dyson, and T. J. Immel (2005), Southern Hemisphere ionosphere and plasmasphere response to the interplanetary shock event of 29-31 October 2003, J. Geophys. Res., 110, A09S30, doi:10.1029/2004JA010920.

R. de Jesus and Y. Sahai, Instituto de Pesquisa e Desenvolvimento, Universidade do Vale do Paraíba, Av. Shishima Hifumi, 2911, 12244-395 São José dos Campos, SP, Brazil.
M. B. Moldwin, Department of Atmospheric, Oceanic and Space Sciences, University of Michigan, Ann Arbor, MI 48109-2143, USA.

E. Yizengaw, Institute for Scientific Research, Boston College, St. Clement's Hall 423, 140 Commonwealth Avenue, Chestnut Hill, MA 02467, USA. (kassie@bc.edu) 